\title{
HEALTH LITERACY STATE OF PARENTS WHO REFUSE VACCINES IN THE IMMUNIZATION SCHEDULE OF THEIR CHILDREN
}

\author{
Can MUGAN¹, Hakan DEMIRCI² \\ ${ }^{1}$ Kurtulus Family Health Center, Bursa, TURKEY \\ 2 Department of Family Medicine, University of Health Sciences Turkey Bursa Yuksek Ihtisas Training and Research Hospital, Bursa, TURKEY
}

\begin{abstract}
Aim: In this study we aimed to investigate the health literacy state of parents who refused one or more vaccines in the immunization schedule of their children for the first 24 months, and other situations that could be associated with vaccine rejection.

Methods: All of the families who were registered to the Bağlaraltı Family Health center between January 2020 - April 2020 and who refused one or more vaccines in the immunization schedule of their children for the first 24 months were included in this study. The participants were divided into two groups as those with vaccine rejection and those without vaccine rejection. A sociodemographic data form and the European Health Literacy Survey short version were applied using a face-to-face technique.

Results: In the study that we performed with 44 families with vaccine rejection and 44 families without vaccine rejection, statistically no difference was observed between the two groups in terms of educational status, income level, smoking and alcohol usage. Limited-inadequate health literacy was associated with vaccine rejection $(p=0.16)$. In the group with vaccine rejection, the rate of mothers who refused the tetanus vaccine during their pregnancy and the OGTT test was higher than in the control group $(p<0.001)$. The number of primary care applications was lower in the group with vaccine rejection $(p<0.001)$ and it was detected that these families applied less to health care institutions $(p=0.022)$. $59.09 \%$ of the parents indicated that they refused to get their children vaccinated because they found it harmful and $56.82 \%$ of them were influenced by others who refused vaccination.

Conclusions: Low health literacy had a negative effect on decisions of families for vaccination of their children. Vaccine rejection is at the same time associated with less usage of the health care system. Family physicians must reach out to these families and give them the necessary training.

Keywords: Childhood immunization, health literacy, primary care, vaccine rejection
\end{abstract}

Corresponding Author: Can MUGAN can mugan@hotmail.com

Received: December 13, 2021; Accepted: December 16, 2021; Published Online: December 31, 2021

Cite this article as: Mugan, C. \& Demirci, H. (2021). Health Literacy State of Parents Who Refuse Vaccines in the Immunization Schedule of Their Children 1(3), 83-92. 


\section{Introduction}

Vaccine rejection dates back to the 1800s. In 1853, the English government made it compulsory for the public to be vaccinated against smallpox during the epidemic without a comprehensive enlightenment force of circumstances and individuals who refused to be vaccinated were subject to harsh penalties including prison. These practices were met with great reaction by the people and forced imposition caused rejection due to its nature (1). The main reason of rejections in those days was the belief that diseases were God's punishments and trying to treat them meant standing up to God (2). In 1885, tens of thousands of people took to the streets of England in opposition to compulsory smallpox vaccinations. Following this well-attended act, the English government decided to sustain smallpox vaccination program but by revoking the punishments against the ones who refused vaccination, thus laid the foundations of conscientious objection (3).

In 1907, the first Anti-Vaccination Conference was held in the United States of America and in 1908 The AntiVaccination League of America was created in Philadelphia. In the same years, a resistance movement against vaccines started in Brazil (2).

Thanks to the increase in awareness with developing age and information and government policies, antivaccination resistance was broken, however a new increase has been observed in anti-vaccination discourse within the last 2 decades. For this reason, WHO founded the Vaccine Hesitancy Working Group in March, 2012 (4).

WHO groups the factors hindering vaccination under three main topics. These are; contextual reasons, individual and group effects, effects regarding vaccines and vaccination (4). These reasons must be well understood to prevent vaccine rejection and the solution created must resolve the factors which cause one or more vaccine rejection with a multifactorial approach.

Vaccine rejection cases, which were very few in our country in the beginning, have showed a sharp increase with the winning of a lawsuit about "taking consent from the parent for vaccination" in 2015 and with frequent media coverage of anti-vaccination discourses. Whereas number of families who do not want to get their children vaccinated was 183 in 2011, this figure increased to 980 in 2013, 5 thousand 400 in 2015 and 12 thousand in 2016, and number of cases about vaccine rejection reached the level of 23 thousand as of 2018 (5).

In this study, we aim to investigate the health literacy states of the parents who refuse one or more vaccines in the immunization schedule of their children for the first 24 months and other situations which could be associated with vaccine rejection.

\section{METHODS}

This study was conducted on families registered to University of Health Sciences, Bursa Yuksek Ihtisas Training and Research Hospital, Bağlaraltı Family Health Center between January 2020 - April 2020 and who refused one or more vaccines in the immunization schedule of their children for the first 24 months applied within the framework of the Expanded National Program on Immunization. Children without vaccination rejection and with the closest date of birth were chosen as the control group.

The dissertation named "Vaccine Rejection in the Population Registered to Bağlaraltı Family Health Center and Related Factors" was approved by the Clinical Research Ethics Committee of Bursa Yuksek Ihtisas Training and Research Hospital, University of 
Health Sciences, with the resolution and approval dated 13.11.2019, no 2011-KAEK-25 2019/11-17.

Socio-demographic data form, HLS-EU Short Version European Health Literacy Survey and a form of questions interrogating the patient's past medical decisions and his/her reason of vaccine rejection were used in the research.

European Health Literacy Survey Short Version (HLSEU Q16): This survey was developed by European Health Literacy Consortium within the context of European Health Literacy Research between 20092012 (6). Validity-reliability study to determine HL level in Turkey was conducted in 2018 by Emiral et al. and it consisted of 16 questions which can be answered by the participants as "very difficult, difficult, easy, very easy and I don't know" (7). This survey is based on the principle of the individual's self-perception of how "easy" or how "difficult" the behavior is indicated in each question. In our study, the questions were read to the participants one by one and they were asked to choose the most appropriate answer for themselves. In the scoring process, choices of very difficult and difficult were scored as 0 and choices of easy and very easy were scored as 1 . Participants who ticked the choice "I don't know" in 3 or more questions were left out of assessment. Total score was obtained by adding the scores of all questions. Score (0-8) was assessed as inadequate $\mathrm{HL}$, score (9-12) was assessed as problematic $\mathrm{HL}$ and score (12-16) was assessed as sufficient $\mathrm{HL}$.

In accordance with our observations in vaccine rejection process, a short form of five questions which interrogate the reasons of vaccine rejection and circumstances that can be associated with the parents' vaccine rejection attitude was used. This form consists of questions interrogating whether the individuals who refuse vaccines have had $\mathrm{Td}$ and oral glucose tolerance test (OGTT) during their pregnancy, as well as their reason of vaccine rejection. In this form, the patient can make appropriate choices for herself/himself and the questions interrogate whether they refuse all vaccines or some specific ones and also vaccination status of their other children, if exist.

\section{Statistical Analysis}

Conformity of the variables to normal distribution was analyzed with Shapiro Wilk test. In case of conformity to normal distribution, continuous variables are expressed with mean \pm standard deviation, in case non-conformity they are expressed with median (minimum: maximum) values. Categorical variables are expressed with $\mathrm{n}(\%)$. In inter-group comparisons of categorical variables, Pearson chi-square, Fisher's exact chi-square test or Fisher Freeman-Halton tests were used. Mann Whitney $\mathrm{U}$ test and Student's T test were used in comparison of two groups according to the normality test result. In case of non-conformity with normal distribution, it was expressed with median, IQR, min, max. SPSS (IBM Corp. Released 2012. IBM SPSS Statistics for Windows, Version 21.0. Armonk, NY: IBM Corp.) program was used for statistical analysis and $\mathrm{p}<0.05$ was statistically accepted significant.

\section{RESULTS}

In the study which was conducted on 44 participants with vaccine rejection and 44 without vaccine rejection, no difference was detected between the two groups in terms of gender, income level, parental marital status, maternal education, profession, alcohol usage and smoking. Paternal education was higher in the group with vaccine rejection (Table1). 
Table1. Comparison of the general characteristics of the participants and parents

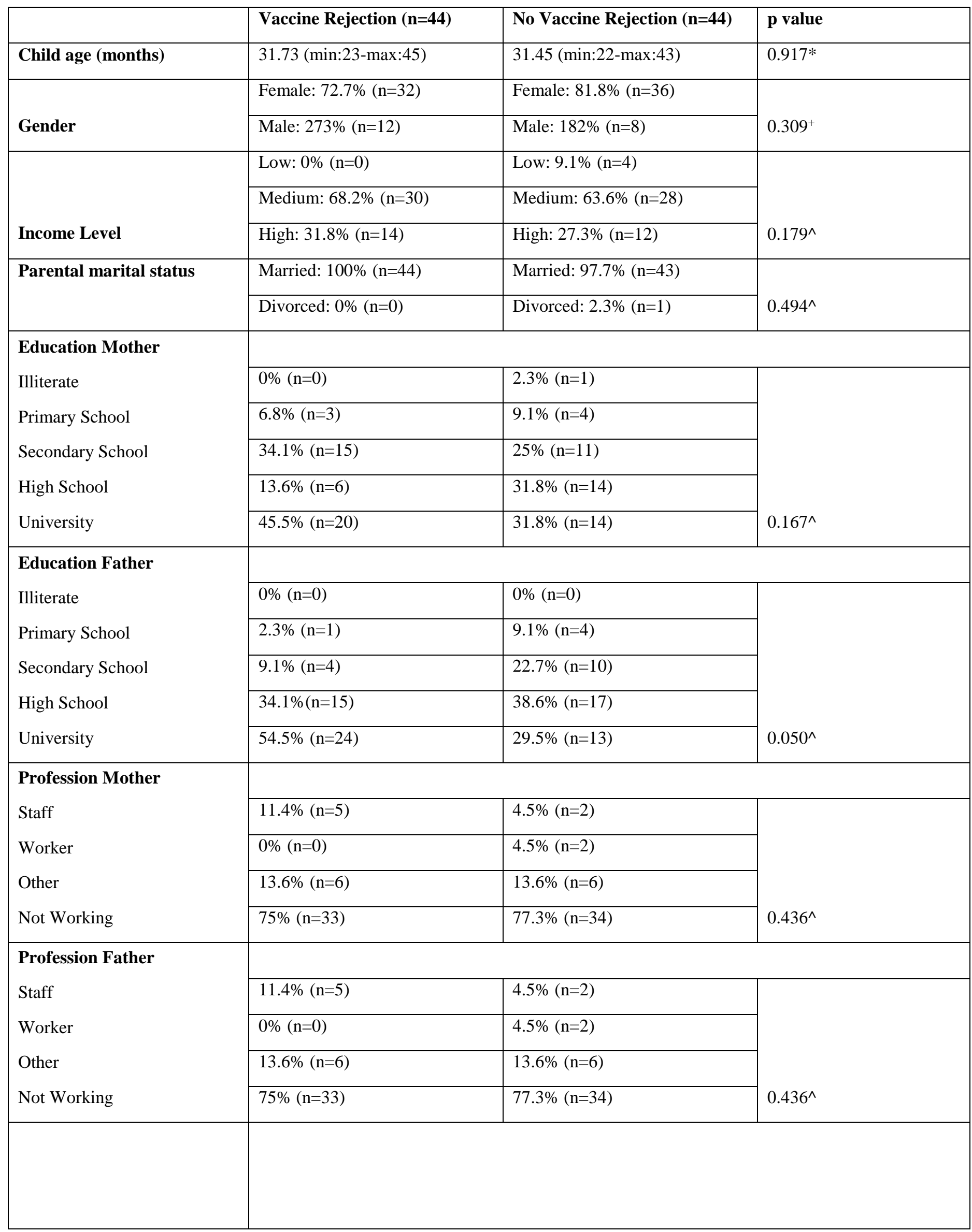




\begin{tabular}{|c|c|c|c|}
\hline Smoking & & & \\
\hline \multicolumn{3}{|l|}{ Mother } & \multirow[b]{3}{*}{$0.772^{\wedge}$} \\
\hline Yes & $11.4 \%(n=5)$ & $18.2 \%(\mathrm{n}=8)$ & \\
\hline Quitted & $2.3 \%(\mathrm{n}=1)$ & $2.3 \%(\mathrm{n}=1)$ & \\
\hline Father & & & \multirow[b]{3}{*}{$0.122^{\wedge}$} \\
\hline Yes & $29.5 \%(n=13)$ & $50 \%(n=22)$ & \\
\hline Quitted & $4.5 \%(n=2)$ & $6.8 \%(\mathrm{n}=3)$ & \\
\hline \multicolumn{4}{|l|}{ Alcohol } \\
\hline \multicolumn{3}{|l|}{ Mother } & \multirow[b]{4}{*}{-} \\
\hline Always & $0 \%$ & $0 \%$ & \\
\hline Sometimes & $0 \%$ & $0 \%$ & \\
\hline Never & $100 \%(n=44)$ & $100 \%(n=44)$ & \\
\hline \multicolumn{3}{|l|}{ Father } & \multirow[b]{4}{*}{$0.241^{\wedge}$} \\
\hline Always & $0 \%$ & $0 \%$ & \\
\hline Sometimes & $0 \%$ & $6.8 \%(\mathrm{n}=3)$ & \\
\hline Never & $100 \%(n=44)$ & $93.2 \%(n=41)$ & \\
\hline
\end{tabular}

*Mann Whitney U test, ${ }^{+}$Chi-square analysis, ${ }^{\wedge}$ Fisher-Freeman-Halton test

Limited-inadequate health literacy is associated with vaccine rejection $(p=0.16)$ (Figure1).

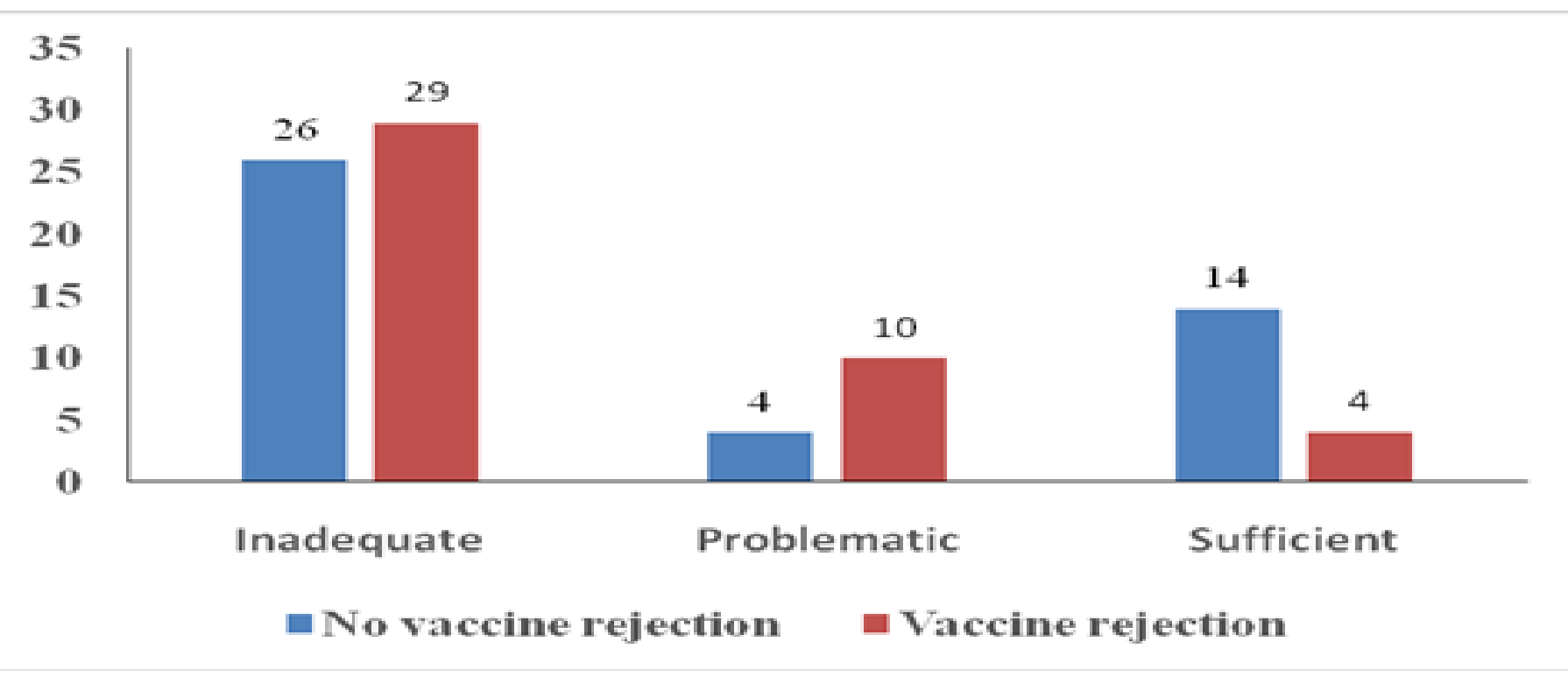

Figure1. Health literacy and vaccine rejection

Td and OGTT rates of the participants during pregnancy are shown in Table 2. It was detected that rate of tetanus vaccination and oral glucose tolerance test rejections during pregnancy was higher in the group with vaccine rejection, with respect to the control group $(p<0.001)$. 
Table2. Td vaccination and OGTT rates of the participants during their pregnancies

\begin{tabular}{|c|c|c|c|c|c|c|}
\hline & & \multicolumn{4}{|c|}{ Vaccine Rejection } & \\
\hline & & \multicolumn{2}{|c|}{ No } & \multicolumn{2}{|c|}{ Yes } & \\
\hline & & Number & Percentage & Number & Percentage & $p$ value \\
\hline \multirow{3}{*}{$\begin{array}{l}\text { Td vaccination in } \\
\text { pregnancy }\end{array}$} & No & 3 & $6.82 \%$ & 23 & $52.27 \%$ & \multirow{3}{*}{$<0.001$} \\
\hline & Yes & 39 & $88.64 \%$ & 18 & $40.91 \%$ & \\
\hline & $\begin{array}{l}\text { Vaccinated } \\
\text { previously }\end{array}$ & 2 & $4.55 \%$ & 3 & $6.82 \%$ & \\
\hline \multirow[t]{2}{*}{ OGTT in pregnancy } & No & 18 & $40.91 \%$ & 38 & $86.36 \%$ & \multirow{2}{*}{$<0.001$} \\
\hline & Yes & 26 & $59.09 \%$ & 6 & $13.64 \%$ & \\
\hline
\end{tabular}

${ }^{+}$Fisher-Freeman-Halton test

Vaccination status of other children of vaccine refusing parents is shown in Table 3. 19 of 44 vaccine rejection cases didn't have other children. Other children were not vaccinated in $52 \%$ of the remaining 25 cases.

Table3. Vaccination Status of the Other Children of the Parents who Refuse Vaccines

\begin{tabular}{|l|l|c|c|}
\hline \multicolumn{2}{|c|}{} & Number & Percentage \\
\hline \multirow{4}{*}{ Vaccination status of other children } & No & 13 & $29.55 \%$ \\
\cline { 2 - 4 } & Yes & 10 & $22.73 \%$ \\
\cline { 2 - 4 } & Partly & 2 & $4.55 \%$ \\
\cline { 2 - 4 } & No other children & 19 & $43.18 \%$ \\
\hline
\end{tabular}

Number of health institution visits of the participants within last 1 year is given in Table 4. Number of primary care application of the group with vaccine rejection was lower $(p<0.001)$ and also they visited less health institutions $(p=0.022)$. 
Table4. Number of the participants' visit to health institutions in the last 1 year and vaccine rejection

\begin{tabular}{|c|c|c|c|c|c|c|c|c|c|}
\hline & & & & $\begin{array}{l}\text { Vac } \\
\text { Rej }\end{array}$ & & & & & \\
\hline & & $\mathbf{N}$ & & & & $Y e$ & & & \\
\hline & Median & IQR & Min. & Max. & Median & IQR & Min. & Max. & p value* \\
\hline $\begin{array}{l}\text { Number of } \\
\text { applications to } \\
\text { primary care }\end{array}$ & 10.00 & 8.00 & 1.00 & 24.00 & 4.00 & 6.00 & .00 & 22.00 & $<0,001$ \\
\hline $\begin{array}{l}\text { Number of } \\
\text { application hospital }\end{array}$ & 7.00 & 8.00 & 1.00 & 38.00 & 5.00 & 6.00 & .00 & 14.00 & 0.022 \\
\hline
\end{tabular}

*Mann Whitney U test

As vaccine rejection reasons, $59.09 \%$ of the $56.82 \%$ of them were influenced by other people participants indicated that they found it harmful and around them who didn't get vaccinated (Figure2).

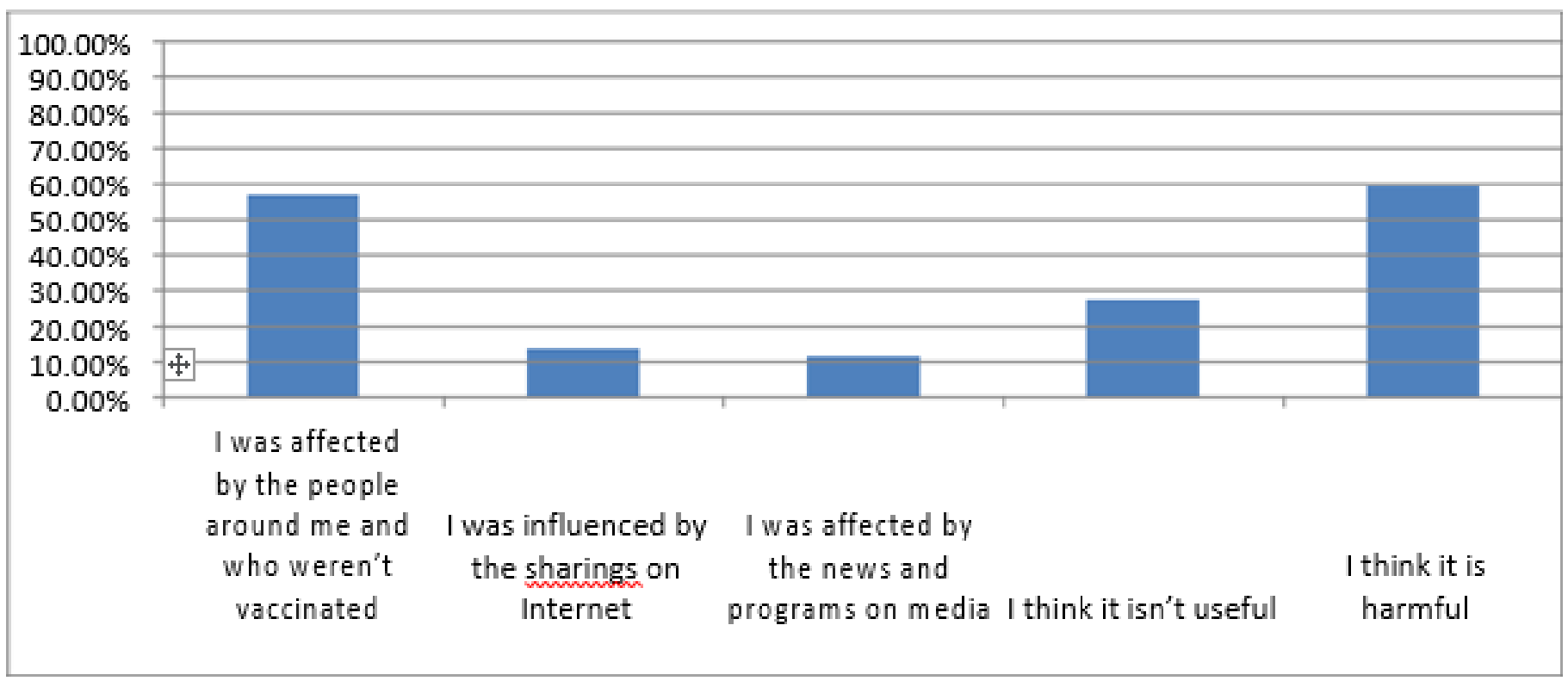

Figure2. Distribution of vaccine rejection reasons of the parents who refuse vaccination

\section{DISCUSSION}

Limited-inadequate health literacy is associated with vaccine rejection. Rate of tetanus vaccination and oral glucose tolerance test rejections during pregnancy was higher in the group with vaccine rejection with respect to the control group. Number of primary care applications of the group with vaccine rejection was lower and also they visited less health institutions. 
$59.09 \%$ of the participants indicated that they found it harmful and $56.82 \%$ of them were influenced by other people around them who didn't get vaccinated.

As a result of our study, education level of the fathers was higher in the group with vaccine rejection. This result, contrary to what is believed, must be considered in the sense of tendency to vaccine rejection of educated families besides low education level. Similarly, in another study, it was detected that families with high education level forget their children's vaccination appointment dates in higher rates (8). In another study, it was shown that there was a close relationship between vaccination rates of the children and mother's education level and vaccination rates increase as the mother's education level increases (9). In a study conducted in USA it was shown that high educational level of the mother positively affects vaccination status (10).

One of the significant findings of our study was that mothers who refuse vaccination of their children had lower rates of Td vaccination and OGTT during their pregnancies with respect to the second group. In our study, whereas rate of avoiding $\mathrm{Td}$ vaccination during pregnancy of the mothers refusing vaccination for their children was $52.27 \%$, this rate was $6.82 \%$ in the second group. Such a big difference is thoughtprovoking and frightening for maternal Td which has reached the elimination point. In a study conducted by Turan et al. in 2019, Td application rate during pregnancy was found close to the control group of our study, as $77.9 \%$ (11). In a study performed by Maral et al. in 2001, Td rate of the pregnant women was detected as $46.7 \%$ (12). In another study performed by Sağsöz et al. in 2002, the same rate was found as $54.8 \%$ (13). When all these rates were analyzed, it was observed that unfortunately vaccination rates of the group with vaccine rejection were at the levels of the early 2000s. When it is considered that vaccination records in the early 2000s weren't kept as accurate as today, it can be concluded that the picture is worse today.

We faced a similar situation with Td when the OGTT rates of our participants were analyzed. Whereas rate of avoiding OGTT during pregnancy of the mothers refusing vaccination for their children was $86.36 \%$, this rate was $40.91 \%$ in the control group. Prevalence of gestational diabetes in which OGTT is used for diagnosis is between $3-8 \%$ in our country (14). When the risk that can be posed by GDM both for the baby and the mother is considered, it is obvious how important OGTT is for early diagnosis of the disease, if exists. However, unfortunately as in Td, OGTT rejection has also reached critical aspects in patients with vaccine rejection. In a previous study, similar with the control group of our study, OGTT avoidance rate was detected as $34.20 \%$. This rate was $14 \%$ according to another study (15). These different rates in the literature can be associated with socio-economic features of the regions where the studies were conducted and size of the study population.

We asked the group with vaccine rejection why they refused it and we found out that $59.09 \%$ of the participants found it harmful, $27.27 \%$ of them thought it was not useful, $11.36 \%$ of them were affected by the news and programs on media, $13.64 \%$ of them were influenced by the sharings on internet and $56.82 \%$ of them were affected by the people around them who didn't get vaccinated. Another noteworthy finding was that $57.6 \%$ of the group who found the vaccine harmful was at the same time influenced by people around them. In another study with similar rates as our research, $63.9 \%$ of the participants didn't find the vaccines safe and $57.6 \%$ of them didn't find the vaccines useful, $21.9 \%$ of them were influenced by the negative news on media and $15.8 \%$ of them followed anti-vaccine groups (8). These rates support 
our study and their results have higher rates than our study. This situation can be associated with the study's region, socio-economical level and size of the population. In a study conducted in 2019 the most common vaccine rejection reasons were respectively; distrust to the vaccine content (44.0\%) and possible side effects of the vaccines (37.4\%) (16).

According to the results of our study, majority of our participants have a thought of rejection not only for a specific vaccine but for all types of vaccines. Only $4.55 \%$ of the participants indicated that they weren't against BCG vaccine, but they refuse all other vaccines except BCG. When we analyze the literature, in a study conducted by Luthy et al. it was detected that hepatitis $B$ and chickenpox were the mostly refused vaccines because their risks of infectiousness were perceived to be low (17). According to our study, the families who didn't refuse BCG vaccine had met tuberculosis disease in their immediate surroundings before and they had concerns about this disease.

We detected in our study that the parents who refuse vaccination applied less to health institutions for their children. The difference in application to health institutions was significantly much higher in primary care health institutions where immunization program is widely conducted in our country. The occurrence of this situation can be related with the feeling of distrust towards the health institution where vaccination is performed and the related physician or feeling of avoidance from being questioned about not being vaccinated.

Limited-inadequate health literacy is associated with vaccine rejection. Health literacy is associated with positive health behaviors (18). Individuals with high health literacy use the health system more effectively. They participate in screening programs in higher rates. Health literacy positively effects the patients' compliance with medication (19). In this study, effect of health literacy of the families on their decision of the vaccination of their children was exhibited.

As a conclusion, low health literacy negatively effects the families' vaccination decision on their children. Vaccine rejection is also associated with less usage of the health system. Family physicians must reach out these families and give them the necessary trainings.

\section{CONFLICT OF INTEREST}

The authors declare that there is no conflict of interest. 


\section{References}

1. Bozkurt HB. Aşı Reddine Genel Bir Bakış ve Literatürün Gözden Geçirilmesi. Kafkas Tıp Bilimleri Dergisi. 2018; 8(1): 71-76.

2. Wolfe RM, Sharp LK. Anti-vaccinationists past and present. BMJ. 2012; 325(7361): 430-432.

3. Swales JD. The Leicester anti-vaccination movement. The Lancet. 1992; 340(8826): 1019-1021.

4. Report of The Sage Working Group On Vaccine Hesitancy. Avaliable at: https://www.who.int/immunization/sage/meeti ngs/2014/october/1_Report_WORKING_GROU P_vaccine_hesitancy_final.pdf. Access Date: 26042020 .

5. Gur E. Aşı kararsızlığı-aşı reddi. Türk Pediatri Arşivi. 2019; 54(1): 1-2.

6. Emiral GO, Aygar H, Isiktekin B, et al. Health literacy scale-European Union-Q16: a validity and reliability study in Turkey. Int. Res. J. Medical Sci. 2018; 6(1): 1-7.

7. HLS-EU Consortium. Comparative report of health literacy in eight EU member states. The European Health Literacy Survey HLS-EU. 2012.

8. Ilter H. Doktora tezi, Konya ilinde çocukluk çağı aşı reddi konusunda anne-baba görüşleri ve aşılamayı etkileyen faktörler. Necmettin Erbakan Sağlık Bilimleri Enstitüsü Halk Sağlığı Anabilim Dalı. 2020.

9. Gulcu S, Arslan S. Çocuklarda Aşı Uygulamaları: Güncel Bir Gözden Geçirme. Düzce Üniversitesi Sağlık Bilimleri Enstitüsü Dergisi. 2018; 8(1): 34-43.

10. Gust DA, Strine TW, Maurice $E$, et al. Underimmunization among children: effects of vaccine safety concerns on immunization status. Pediatrics. 2004; 114(1): e16-e22.

11. Turan G, Kul G. Gebelerde tetanoz immünizasyonu: Maternal degerlendirme, tetanoz asilama durumu ve asilama oranini etkileyen faktörler. Perinatoloji Dergisi, 2019; 27(3): 137-142.

12. Maral I, Baykan Z, Aksakal FN, Kayikcioglu F, Bumin MA. Tetanus immunization in pregnant women: evaluation of maternal tetanus vaccination status and factors affecting rate of vaccination coverage. Public Health. 2001; 115(5): 359-364.

13. Sagsoz N, Apan T. Gebelerde tetanoz, hepatit $B$ ve rubella seropozitiflik oranları. Journal of Clinical Obstetrics \& Gynecology. 2002; 12(1): 52-55.

14. Yaprak M, Gümüştakım RS, Tok A, Doganer A. Gebelerde Oral Glukoz Tolerans Testi Farkındalığının Tespiti. Ankara Medical Journal. 2019; 19(3): 635-647.

15. Desdicioglu R, Yildirim M, Suleymanova I, Atalay I, Ozcan M, Yavuz AF. Gebe Kadınların Antenatal Testlere Yaklaşımını Etkileyen Faktörler. Ankara Med J 2017; 17(1): 57-64.

16. Yalcin BNB, Tunc AY, Sasmaz CT. Mersin İl Merkezinde Çalışan Aile Sağlığı Elemanlarının Aşı Kararsızığı veya Reddi İle Karşılaşma Durumu Ve İlişkili Faktörlerin Araştııılması. In 3. International 21. National Public Health. 2019.

17. Luthy KE, Beckstrand RL, Callister LC, Cahoon $\mathrm{S}$. Reasons parents exempt children from receiving immunizations. The Journal of School Nursing. 2012; 28(2): 153-160.

18. Ciftci F, Demirci H, Ciftci HN, Ocakoglu G. Validation of Turkish Version of Newest Vital Sign Scale to Assess Health Literacy. Bezmialem Science, 2021; 9(2): 219.

19. Turkoglu AR, Demirci $H$, Coban S, et al. Evaluation of the relationship between compliance with the follow-up and treatment protocol and health literacy in bladder tumor patients. The Aging Male. 2018. 